ФИЗИЧЕСКАЯ ГЕОГРАФИЯ, ГЕОФИЗИКА, ГЕОХИМИЯ ЛАНДШАФТОВ 


\title{
ИЗУЧЕНИЕ ИЗМЕНЕНИЯ АНТРОПОГЕННЫХ ЛАНДШАФТОВ В СИХОТЭ - АЛИНСКОМ БИОСФЕРНОМ РАЙОНЕ НА ОСНОВЕ СРАВНЕНИЯ РАЗНОВРЕМЕННЫХ КАРТ АНТРОПОГЕННЫХ УРОЧИЩ
}

\author{
Гуров А. $A$. \\ Тихоокеанский институт географии ДВО РАН, Владивосток \\ alexgurov1987@yandex.ru
}

Аннотация. Изучение изменения ландшафтного покрова под воздействием антропогенных факторов в течении длительного времени важно для понимания процессов, протекающих в ландшафте под воздействием этих факторов. В настоящей работе демонстрируется изменение ландшафтов нескольких ключевых участков под воздействием антропогенных факторов в течении 48 и 30 лет. В основе исследования лежит сравнение разновременных карт антропогенных урочищ рассматриваемых территорий. Исследования проведены в Сихотэ-Алинском биосферном районе. В качестве ключевых участков выбраны крупные населенные пункты - поселок городского типа Кавалерово и г. Дальнегорск. В обоих населенных пунктах функционируют или функционировали объекты горнопромышленного производства, что представляет собой дополнительный интерес для изучения. Материалы, лежащие в основе данной работы, получены в ходе выполнения полевых ландшафтных исследований в 2010-2012 годах и после обработки архивных аэрофотоснимков исследуемых территорий. Ключевой участок «Кавалерово» представляет собой прямоугольник со сторонами приблизительно 6 х 10 км, площадью 63 км². В него входит поселок городского типа Хрустальный, нефункционирующие здания бывшего Хрустальненского горно-обогатительного комбината и комплекс щламовых отвалов. За 48-летний период суммарная площадь антропогенных урочищ ключевого участка увеличилась на 3 км$^{2}$ или более чем на $100 \%$ от значений за 1962 г., появились новые типы урочищ. Ключевой участок «Дальнегорск» представляет собой прямоугольник со сторонами приблизительно 9 х 10 км и площадью 87 км². В него входит часть города Дальнегорск, горно-химический комбинат, карьерно-отвальный комплекс, а также комплекс шламовых отвалов. За 30-летний период суммарная площадь антропогенных уро-

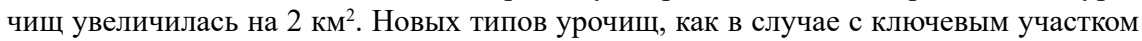
«Кавалерово», за рассматриваемый период не сформировалось. Также в работе для обоих ключевых участков приведены данные соотношения площадей, занимаемых антропогенными урочищами в разные годы, и разновременные карты антропогенных урочищ.

Ключевые слова: изменение ландшафта, ландшафтная карта, урочище, антропогенный ландшафт, горнопромышленные территории. 


\title{
STUDY OF CHANGES IN ANTHROPOGENIC LANDSCAPES \\ IN THE SICHOTE-ALIN BIOSPHERE REGION BASED ON THE COMPARISION OF DIFFERENT-TIME MAPS OF ANTHROPOGENIC MESO-LANDSCAPES
}

\author{
Gurov A.A. \\ Pacific Geographical Institute FEB RAS, Vladivostok
}

Annotation. The study of changes in landscape cover under the influence of anthropogenic factors over a long period of time is potentially capable of giving an understanding of the processes occurring in the landscape under the influence of these factors. The present work, on the example of comparing paired multi-temporal maps of anthropogenic meso-landscapes, clearly demonstrates the change in landscapes of several key areas under the influence of anthropogenic factors over 48 and 30 years. Research conducted in the Sikhote-Alin biosphere region. The key areas selected large settlements - Kavalerovo and Dalnegorsk. The materials underlying this work were obtained in the course of field landscape research in 2010-2012 and the processing of archival aerial photographs of the studied territories. The key area «Kavalerovo» is a rectangle with sides of approximately $6 \mathrm{~km} \times 10 \mathrm{~km}$ and an area of $63 \mathrm{~km}^{2}$. It includes the urban-type settlement Khrustalnyi, non-functioning buildings of the mining and processing plant and a complex of sludge storages. Over the 48-year period, the total area of anthropogenic meso-landscapes of the key area increased by $3 \mathrm{~km}^{2}$ or more than $100 \%$. The key area «Dalnegorsk» is a rectangle with sides of approximately $9 \mathrm{~km} \times 10 \mathrm{~km}$ and an area of $87 \mathrm{~km}^{2}$. It includes part of the city of Dalnegorsk, a mining and chemical combine, a waste dump complex, and a complex of sludge dumps. Over the 30 year period, the total area of anthropogenic meso-landscapes increased by $2 \mathrm{~km}^{2}$. Also in the work for both key areas, data on the ratio of the areas occupied by anthropogenic meso-landscapes in different years and different-time maps of anthropogenic meso-landscapes are presented.

Key words: landscape change, landscape map, meso-landscape, anthropogenic landscape, mining industry.

Изучение изменения природных ландшафтов под воздействием антропогенных факторов является одним из важнейших направлений в географии. С каждым годом количество площадей природных ландшафтов, вовлекаемых в хозяйственную деятельность, растет. Например, существующие населенные пункты расширяются, усложняется их техническая составляющая, новые площади отводятся под различные производственные и обрабатывающие комплексы, агропроизводственные земли. Исследование изменения ландшафтного покрова под воздействием антропогенных факторов в течении длительного времени важно для понимания процессов, протекающих в ландшафте под воздействием этих факторов. Особенно полезным будет выполнение 
такой работы на крупномасштабных и среднемасштабных уровнях (урочищ, фаций). Цель данной работы - продемонстрировать на примере сравнения парных разновременных карт антропогенных урочищ изменение ландшафтов ключевых участков «Кавалерово» (пгт. Кавалерово, Приморский край) и «Дальнегорск» (г. Дальнегорск, Приморский край) под воздействием антропогенных факторов в течении 48 и 30 лет. Для этого была поставлена задача построить парные разновременные карты ключевых участков на основе разработанной классификации антропогенных урочищ [5], провести их сравнение.

Сихотэ-Алинский биосферный район расположен в юго-восточной части Сихотэ-Алинской складчатой системы. Границы района на восточном макросклоне охватывают территорию от бассейнов рек Лиственная и Кема на севере до бассейна реки Зеркальная на юге. На западном макросклоне границы района охватывают бассейн верхней половины реки Большая Уссурка и верхние части бассейнов рек Журавлевка и Павловка (в границах Кавалеровского района и Дальнегорского округа). Площадь Сихотэ-Алинского биосферного района

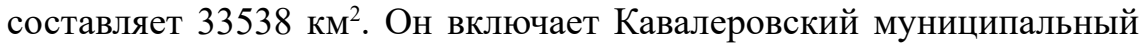
район и Дальнегорский городской округ полностью, и Красноармейский и Тернейский муниципальные районы частично.

Полевые исследования ключевых участков проведены в 20102012 гг. Выделены классы урочищ трёх классификационных рангов (термин «класс» используется как безранговый, применимый к классификационным единицам любого ранга). Для выделения классов высшего (первого) ранга использованы два основания. Первое - схема, в которой Ф.Н. Мильков [3] для каждого отдела ландшафтов (наземного, земноводного и др.) выделяет два ряда или порядка - естественный и антропогенный, а В.И. Федотов [8] различает два отдела техногенных ландшафтов - наземный и земноводный. Второе - представления о геотехнических $[1,6]$ или ландшафтно-технических [3] системах. Это позволило выделить такие классы геокомплексов/геосистем, как техно-природные наземные, техно-природные земноводные, техно-природные водные, природно-технические наземные и природно-технические земноводные. Классы второго ранга примерно соответствуют типам, реже классам, антропогенных ландшафтов Ф.Н. Милькова [2, 4] и М.Л. Рева [7].

Разновременные карты антропогенных урочищ исследуемого ключевого участка составлены с использованием программного обеспечения ArcGIS 10, на основе полевых материалов, спутнико- 
Рис. 1. Карты антропогенных урочищ ключевого участка «Кавалерово» $(a-1962$ г., $\sigma-2010$ г., в наложение карт, где штриховкой отмечена карта за 1962 г., серым за 2010 г.)

Условные обозначения. Природно-технические наземные урочища: среднеэтажная застройка: 1 - производственная застройка на покатых участках, 2 - жилая застройка на покатых участках, 4 застройка с недействующими строениями на крутых участках; малоэтажная застройка: 5 - производственная застройка на покатых участках, 8 - застройка с недействующими строениями на покатых участках; транспортные магистрали: 10 - автодороги II-V-ой категорий; отваль промышленных $и$ бытовых отходов: 12 - отвалы шламовые. Природно-технические земноводные урочища: каналь: 14 - каналы бетонные. Техно-природные наземные урочища: усадебная и дачная застройка: 16 - сельская застройка на покатых участках; агропроизводственные земли: 23 - сельскохозяйственные поля в речных долинах, 24 - сельскохозяйственные поля на покатых склонах. Техно-природные земноводные урочища: мелководья антропогенные: 26 - обводненные карьеры, котлованы и т.п.; канализированные водотоки: 27 - канализированные русла рек.
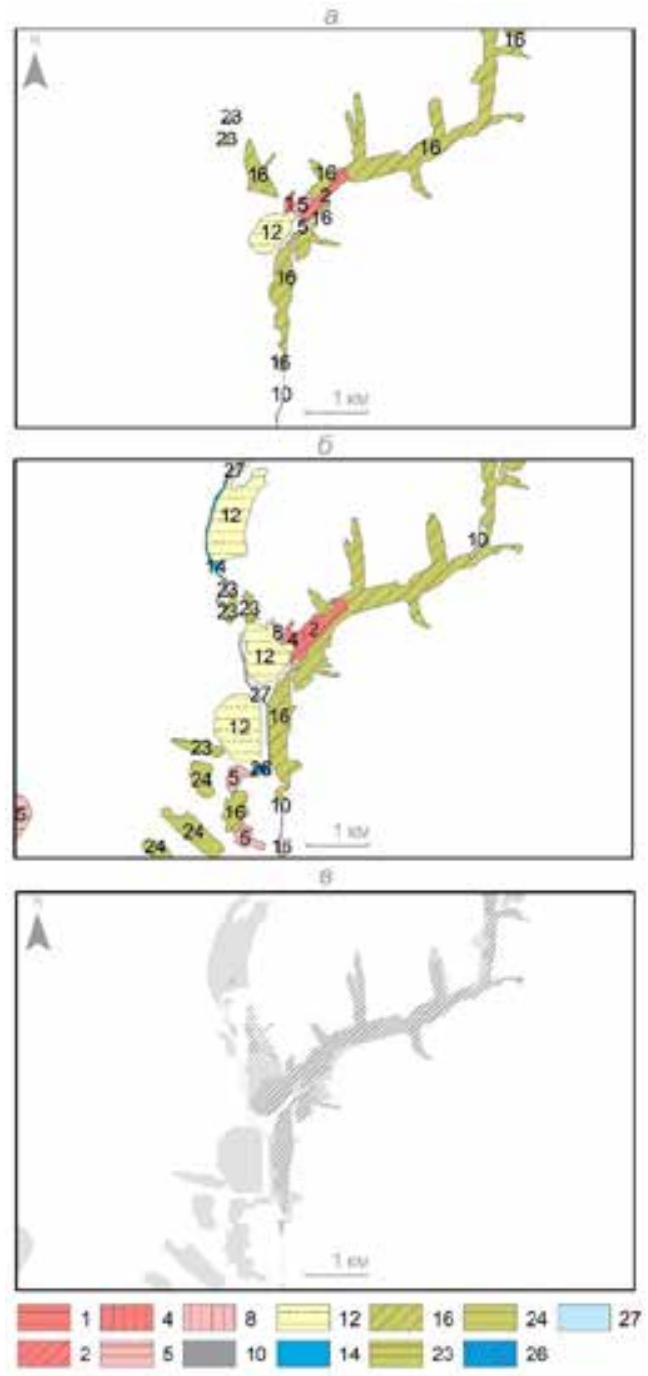

вых снимков высокого разрешения, топографических карт масштаба 1:100000, аэрофотоснимков. Масштаб карт 1:50 000.

Ключевой участок «Кавалерово» представляет собой прямоугольник со сторонами приблизительно 6 х 10 км, площадью 63 км². В него входит поселок городского типа Хрустальный, нефункционирующие здания бывшего Хрустальненского ГОКа и комплекс щламовых отвалов. Данные об изменении антропогенных урочищ получены на ос- 
нове сравнения карт урочищ за 2010 г. и 1962 г. (рис. 1). Основой для составления ландшафтных карт являлись материалы полевых исследований 2010 г. и аэрофотоснимки 1962 г. Таким образом, временной промежуток между анализируемыми материалами составляет 48 лет.

Как видно из таблицы 1, за 48-летний период суммарная пло-

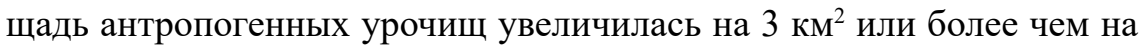
$100 \%$. Если рассматривать увеличение площади типов антропогенных урочищ относительно их исходного состояния (на 1962 год), то преобладают агропроизводственные земли, их площадь увеличилась в 30 раз. Большой прирост отмечается в отвалах промышленных и бытовых отходов, а также в малоэтажной застройке - в 6 раз. Кроме того, появились новые типы урочищ: каналы - $2 \%$ от всей добавившейся площади, мелководья антропогенные - $1 \%$ и канализированные водотоки - 1,5 \% соответственно. Основной вклад в рост площади антропогенных урочищ за рассматриваемый период вносит увеличение отвалов промышленных и бытовых отходов за счет формирования двух новых шламохранилищ и укрупнения уже существовавшего на 1962 год. Всего рост для них составил порядка 51 \% от всей добавившейся площади.

Таблица 1

Соотношение площадей, занимаемых антропогенными урочищами в разные годы для ключевого участка «Кавалерово»

\begin{tabular}{|l|c|c|}
\hline \multicolumn{1}{|c|}{ Тип урочищ } & $\begin{array}{c}\text { Площадь } \\
\text { антропогенных } \\
\text { ландшафтов } \\
\text { в 1962 г (км })^{2}\end{array}$ & $\begin{array}{c}\text { Площадь } \\
\text { антропогенных } \\
\text { ландшафтов } \\
\text { в 2010 г (км²) }\end{array}$ \\
\hline Среднеэтажная застройка & 0,2 & 0,3 \\
\hline Малоэтажная застройка & 0,1 & 0,4 \\
\hline Плотины & - & - \\
\hline Транспортные магистрали & 0,01 & 0,03 \\
\hline Отвалы промышленных и бытовых отходов & 0,3 & 2 \\
\hline Каналы & - & - \\
\hline Причалы & - & - \\
\hline Усадебная и дачная застройка & 3 & - \\
\hline Сельскохозяйственные строения & - & - \\
\hline Площадки с отдельными строениями & - & - \\
\hline Отвалы поверхностных горных пород & - & 1 \\
\hline Обнажения горных пород & - & - \\
\hline Агропроизводственные земли & 0,03 & - \\
\hline Озелененные территории & - & - \\
\hline
\end{tabular}


Окончание табл. 1

\begin{tabular}{|l|c|c|}
\hline \multicolumn{1}{|c|}{ Тип урочищ } & $\begin{array}{c}\text { Площадь } \\
\text { антропогенных } \\
\text { ландшафтов } \\
\text { в 1962 г }\left(\mathrm{\kappa м}^{2}\right)\end{array}$ & $\begin{array}{c}\text { Площадь } \\
\text { антропогенных } \\
\text { ландшафтов } \\
\text { в 2010 г }\left(\mathrm{\kappa м}^{2}\right)\end{array}$ \\
\hline Мелководья антропогенные & - & 0,03 \\
\hline Канализированные водотоки & - & 0,05 \\
\hline Водоёмы антропогенные & - & - \\
\hline Суммарно км $^{2}$ & 3 & 7 \\
\hline
\end{tabular}

Ключевой участок «Дальнегорск» представляет собой прямоугольник со сторонами приблизительно 9 х 10 км и площадью 87 км² $^{2}$ В него входит часть города Дальнегорск, горно-химический комбинат, карьерно-отвальный комплекс, а также комплекс шламовых отвалов. Данные об изменении антропогенных урочищ получены на основе сравнения карт урочищ за 2012 г. и 1982 г. (рис. 2). Основой для составления карт являлись материалы полевых исследований 2012 г и аэрофотоснимки 1982 г. Временной период между рассматриваемыми материалами составляет 30 лет.

Из таблицы 2 видно, что за 30-летний период суммарная площадь антропогенных урочищ увеличилась на 2 км² $^{2}$ В среднем на долю каждого типа урочищ пришлось небольшое увеличение площади, особо можно выделить три типа урочищ: среднеэтажная застройка, отвалы поверхностных горных пород и водоемы антропогенные. Наиболее заметные изменения видны в отвалах поверхностных горных пород,

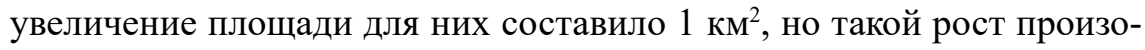
шел в том числе и за счет снижения доли обнажений горных пород -

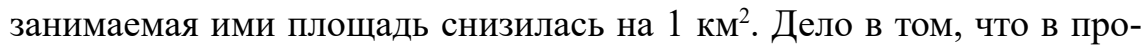
цессе горнопромышленной деятельности отвалы отсыпались поверх стенок карьеров, так происходило замещение одного типа урочищ другим. Кроме того, на 1982 год в Дальнегорске одно из водохранилищ только формируется и представляет собой карьер размером 0,4 км², но уже к 1985 году оно заполнено водой.

В течение рассматриваемого периода происходит замещение усадебной и дачной застройки среднеэтажной застройкой, что связано с ростом численности населения и вероятной нехваткой доступных для возведения жилья земель (сильнопересеченная местность). Площадь,

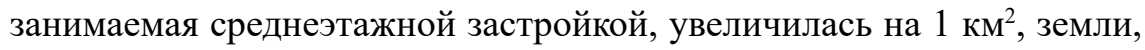
занятые под усадебную и дачную застройку сократились на 1 км². 

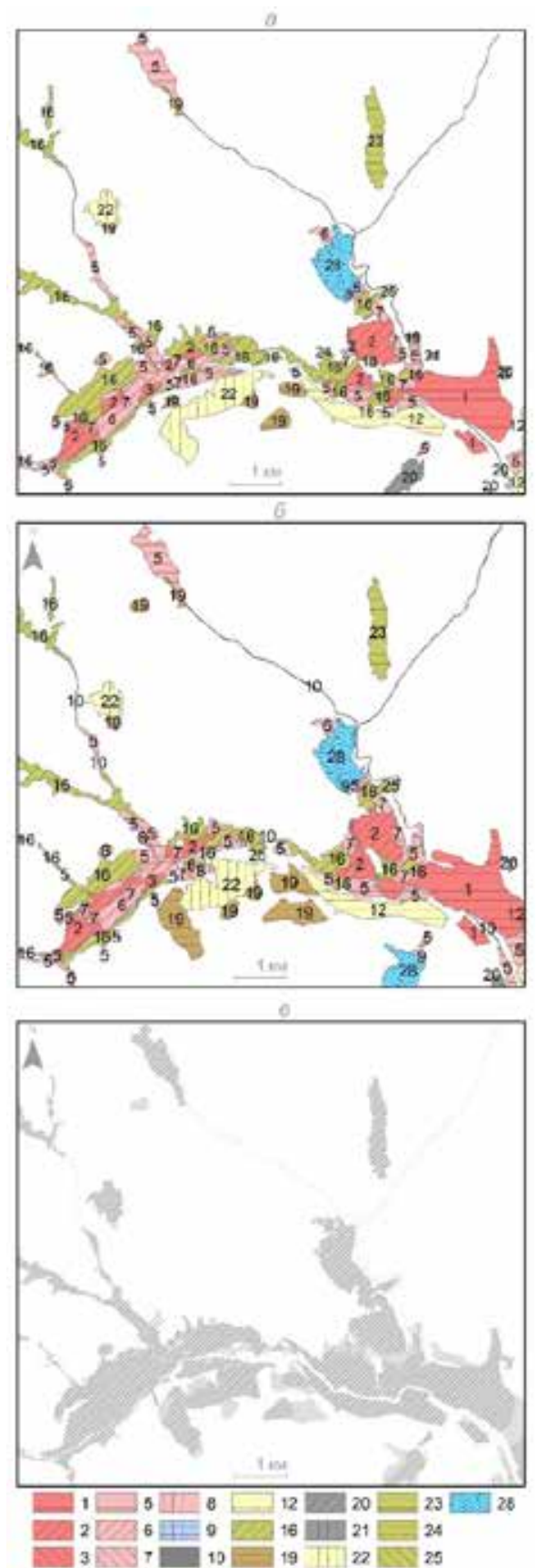

Рис. 2. Карты антропогенных урочищ ключевого участка «Дальнегорск» ( $a$ - 1982 г., б - 2012 г., в - наложение карт, где штриховкой отмечена карта за 1982 г., серым за 2012 г.)

Условные обозначения. Природно-технические наземные урочища: среднеэтажная застройка: 1 - производственная застройка на покатых участках, 2 - жилая застройка на покатых участках, 3 - застройка общественными зданиями на покатых участках; малоэтажная застройка: 5 - производственная застройка на покатых участках, 6 -жилая застройка на покатых участках, 7 - застройка общественными зданиями на покатых участках, 8 застройка с недействующими строениями на покатых участках; плотины: 9 - плотины малые; транспортные магистрали: 10 - автодороги II-V-ой категорий; отвалы промышленных $u$ бытовых отходов: 12 - отвалы шламовые. Техно-природные наземные урочища: усадебная и дачная застрой$\kappa a: 16$ - сельская застройка на покатых участках; отвалы поверхностных горHых пород: 19 - отвалы поверхностных горных пород; обнажения горных nород: 20 - обнажения рыхлых горных пород покатые, 21 - обнажения рыхлых горных пород крутые, 22 - обнажения скальных горных пород крутые; агропроизводственные земли: 23 сельскохозяйственные поля в речных долинах, 24 - сельскохозяйственные поля на покатых склонах; озеленённые территории: 25 - парки отдыха на покатых участках. Техно-природные земноводные урочища: водохранилища: 28 - долинно-речные водохранилища. 


\section{Соотношение площадей, занимаемых антропогенными урочищами} в разные годы для ключевого участка «Дальнегорск».

\begin{tabular}{|l|c|c|}
\hline \multicolumn{1}{|c|}{ Тип урочищ } & $\begin{array}{c}\text { Площадь } \\
\text { антропогенных } \\
\text { ландшафтов } \\
\text { в 1982 г (км }{ }^{2}\end{array}$ & $\begin{array}{c}\text { Площадь } \\
\text { антропогенных } \\
\text { ландшафтов } \\
\text { в 2012 г (км })^{2}\end{array}$ \\
\hline Среднеэтажная застройка & 3 & 4 \\
\hline Малоэтажная застройка & 3 & 4 \\
\hline Плотины & 0,03 & 0,1 \\
\hline Транспортные магистрали & 0,2 & 0,2 \\
\hline Отвалы промышленных и бытовых отходов & 1 & 1 \\
\hline Каналы & - & - \\
\hline Причалы & - & 3 \\
\hline Усадебная и дачная застройка & 4 & - \\
\hline Сельскохозяйственные строения & - & - \\
\hline Площадки с отдельными строениями & - & 2 \\
\hline Отвалы поверхностных горных пород & 1 & 1 \\
\hline Обнажения горных пород & 2 & 1 \\
\hline Агропроизводственные земли & 1 & 0,1 \\
\hline Озелененные территории & 0,03 & - \\
\hline Мелководья антропогенные & - & - \\
\hline Канализированные водотоки & - & 1 \\
\hline Водоёмы антропогенные & 1 & 17 \\
\hline Суммарно км ${ }^{2}$ & 15 & \\
\hline
\end{tabular}

Основная производственная деятельность для населения в пределах исследуемых ключевых участков за рассматриваемые временные промежутки - горнопромышленное производство. Логично предположить, что основной прирост площади антропогенных ландшафтов для них будет происходить за счет вовлечения новых земель в производственный процесс, т.е. отсыпание новых отвалов, формирование карьеров и т.д. Справедливо такое утверждение оказалось для ключевого участка «Кавалерово», где основной прирост действительно произошел за счет формирования новых и увеличения площади ста-

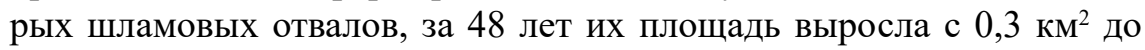

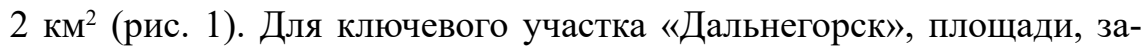
нимаемые под отвалы поверхностных горных пород, шламы и карьеры, остаются практически неизменными. При этом площадь отвалов поверхностных горных пород увеличивается, но происходит это по 
большей части за счет отсыпки новых отвалов в пределах существующих карьеров, общая площадь земель, занятых под горнопромышленное производство, практически не увеличивается. Основной вклад в увеличение площади антропогенных ландшафтов для исследуемого ключевого участка вносят производственная и жилая застройка.

Исследования выполнены при финансовой поддержке Российского фонда фундаментальных исследований (проект № 18-05-00086).

\section{Литература}

1. Дьяконов К. Н. Становление концепции геотехнической системы // Вопросы географии. Сб. 108. М: Мысль, 1978. С. 54-63.

2 . Мильков $Ф$. Н. Антропогенное ландшафтоведение, предмет изучения и современное состояние // Вопросы географии. Сб. 106. М.: Мысль, 1977. С. 11-27.

3. Мильков Ф. Н. Физическая география. Учение о ландшафте и географическая зональность. Воронеж: Изд-во Воронеж. ун-та, 1986. 328 с.

4. Мильков Ф. Н. Физическая география: современное состояние, закономерности, проблемы. Воронеж: Изд-во Воронеж. ун-та, 1981. 400 с.

5. Осипов С.В., Гуров А.А. Ландшафтное картографирование антропогенных урочищ для оценки состояния и мониторинга территории (на примере Сихотэ-Алинского биосферного района) // География и природные ресурсы. 2019. № 3. С. 41-48.

6. Природа, техника, геотехнические системы / Отв. ред. В. С. Преображенский. М.: Наука, 1978. 152 с.

7. Рева М. Л. Возобновления растительного покрова в специфических условиях техногенных ландшафтов Донбасса // Программа и методика изучения техногенных биогеоценозов. М.: Наука, 1978. С. 136-147.

8. Федотов В. И. Техногенные ландшафты: теория, региональные структуры, практика. Воронеж: Изд-во Воронеж. ун-та, 1985. 192 с.

\section{References}

1. Dyakonov K.N. [The development of the geotechnical system concept]. Voprosy geografii [Problems of Geography]. Moscow, Mysl' Publ., 1978, vol. 108, pp. 54-63. (In Russian.).

2. Milkov F.N [Anthropogenic landscape science: object of study and contemporary state]. Voprosy geografii [Problems of Geography]. Moscow, Mysl' Publ., 1977, vol. 106, pp. 11-27. (In Russian.).

3. Milkov F.N. Fizicheskaya geografiya. Uchenie o landshafte i geograficheskaya zonal'nost' [Physical Geography: Study of Landscape and Geographical Zonality]. Voronezh, Voronezh. Univ. Publ., 1986. 328 p.

4. Milkov F.N. Fizicheskaya geografiya: sovremennoe sostoyaniye, zakonomernosti, problemy [Physical Geography: Contemporary State, Patterns, Problems]. Voronezh, Voronezh. Univ. Publ., 1981. 400 p.

5. Osipov S.V., Gurov A.A. Landshaftnoe kartografirovanie antropogennyh urochishch dlya ocenki sostoyaniya i monitoringa territorii (na primere Sihote-Alinskogo biosfernogo 
rajona) [Landscape mapping of anthropogenic meso-landscapes for assessment and monitoring of the territory (examplified by the Sikhote-Alin biosphere region)]. Geografiya $i$ prirodnye resursy - Geography and Natural Resources, 2019, no. 3, pp. 41-48. (In Russian.)

6. Priroda, tekhnika, geotekhnicheskie sistemy [Nature, Technics, Geotechnical Systems]. Preobrazhenskii V.S., Ed. Moscow: Nauka Publ., 1978. 152 p.

7. Reva M.L. [Regeneration of vegetation cover in specific conditions of technogenic landscapes of Donbass]. Programma i metodika izucheniya tekhnogennykh biogeotsenozov [Programme and Methods for the Study of Technogenic Biogeocoenoses]. Moscow, Nauka Publ., 1978, pp. 136-147. (In Russian.)

8. Fedotov V.I. Tekhnogennye landshafty: teoriya, regional'nye struktury, praktika [Technogenic Landscapes: Theory, Regional Structures, Practice]. Voronezh, Voronezh Univ. Publ., 1985. 192 p. 